\title{
Clustering and Hierarchical Organization of 3D Printed Poly(propylene fumarate)-block-PEG-block- Poly(propylene fumarate) ABA Triblock Copolymer Hydrogels
}

Gaëlle Le Fer*1,2, Rodger A. Dilla ${ }^{2}$, Zeyu Wang ${ }^{2}$, Jaelynne King ${ }^{2}$, Steven S. C. Chuang ${ }^{2}$, and Matthew L. Becker*3

${ }^{1}$ Univ. Lille, CNRS, INRAE, Centrale Lille, UMR 8207 - UMET - Unité Matériaux et Transformations, F-59000 Lille, France

${ }^{2}$ Department of Polymer Science, The University of Akron, Akron, Ohio 44325, USA

${ }^{3}$ Departments of Chemistry, Mechanical Engineering and Material Science, Biomedical Engineering, Orthopaedic Surgery, Duke University, Durham, NC 27708, USA

*Corresponding Authors: E-mail: matthew.1.becker@duke.edu, gaelle.lefer@univ-lille.fr

KEYWORDS: 3D printing, hydrogels, amphiphilic copolymers, nanoscale ordering, mechanical properties, degradable.

For table of content only

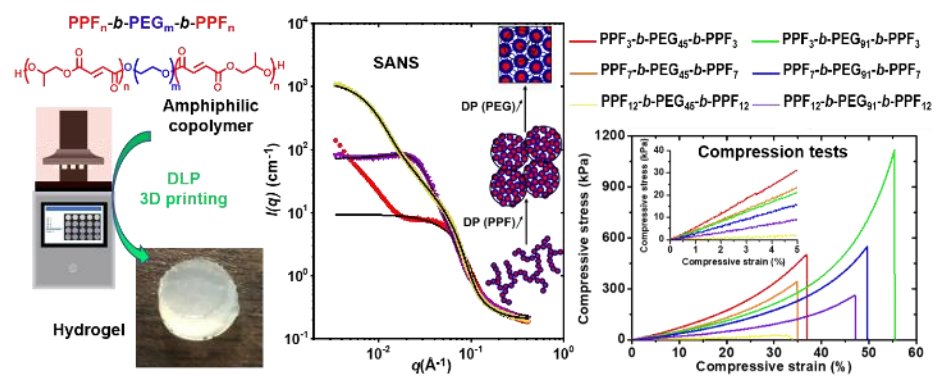




\section{ABSTRACT}

Hydrogels are deployed widely in all areas of regenerative medicine, including bioprinting. The transport and mechanical properties exhibited by hydrogel assemblies are controlled by their organization and hierarchical assembly. This paper points out the role of nanoscale size and ordering of hydrophobic crosslinked domains on the mechanical and degradation properties of 3D printed amphiphilic hydrogels. A series of six poly(propylene fumarate)-block-poly(ethylene glycol)-block-poly(propylene fumarate) (PPF- $b$-PEG- $b$-PPF) ABA triblock copolymers were synthesized by varying both the water-soluble PEG block and the crosslinkable hydrophobic terminal PPF block lengths. Self-assembled hydrogels were formed by dissolving these amphiphilic PPF- $b$-PEG- $b$-PPF copolymers in water and covalently crosslinking the PPF units via digital light processing (DLP) additive manufacturing. Differential scanning calorimetry (DSC), in situ diffuse reflectance infrared spectroscopy (DRIFTS-IR) measurements, small-angle neutron scattering (SANS) and compressive measurements highlight how structural properties correlate with mechanical properties within this hydrogel system. Finally, swelling and in vitro degradation tests showed the influence of the nanoscale ordering on the degradation timescale. 


\section{Introduction}

Spontaneous self- and hierarchical assembly underpins most biological systems, including tissues. ${ }^{1-4}$ To mimic these assemblies and complex structures, biomaterials, including synthetic hydrogels, able to organize at the nanoscale via microphase separation in water, bringing specific macroscopic properties, have shown significant interest and potential. ${ }^{5-8}$ Hydrogels are able to display a broad range of properties making them applicable to many unmet medical needs including depots for therapeutic delivery, ${ }^{9-11}$ contact lenses, ${ }^{12,}{ }^{13}$ coatings and cell scaffolds for tissue engineering. ${ }^{14,15}$ In particular, mechanical properties of hydrogels have been reported as a factor for modifying the differentiation and proliferation behavior of human mesenchymal stem cells (hMSCs) ${ }^{16-20}$ In this context, the design of simple hydrogels and the thorough understanding of their formation process throughout self-assembly phenomena is a critical point toward the development of the future materials for tissue engineering. Simultaneously, elaboration of materials adapted to be used in state-of-the-art technologies such as addictive manufacturing, also known as 3D printing, turns out to be a necessity. ${ }^{21,22}$ Thanks to 3D printing, objects can be generated without the need for molds, enabling a high degree of flexibility in design, contributing in the development of patient specific products.

Block copolymers consist on two or more covalently linked different polymer sequences able to self-assemble into nanostructured materials depending on block incompatibility. The resulting morphology and characteristics on the 10-100 nm length scale results from the balance between maximizing each block entropic degree of freedom and minimizing the contact between the different incompatible block. Linear ABA triblock copolymers undergo specific self-assembly process upon introduction into a B-block selective solvent and was broadly used to form hydrogel in water when a hydrophilic mid B-block is involved. The physical crosslinking in hydrogels 
obtained from ABA triblock copolymers is from the segregation of hydrophobic A-blocks into separated domains, while the B-block bridges two hydrophobic domains. ${ }^{23,24}$ To reinforce the mechanical properties of such hydrogels, chemical crosslinking between hydrophobic blocks is a way to explore.

We previously reported the 3D printing of chemically crosslinked hydrogels based on amphiphilic ABA triblock copolymers, poly(propylene fumarate $)_{n}$-block-poly(ethylene glycol $)_{\mathrm{m}^{-}}$ block-poly(propylene fumarate $)_{\mathrm{n}}\left(\mathrm{PPF}_{\mathrm{n}}-b-\mathrm{PEG}_{\mathrm{m}}-b-\mathrm{PPF}_{\mathrm{n}}\right) .{ }^{25} \mathrm{Poly}($ ethylene glycol) (PEG) has been explored extensively for its use in biomedical applications as a consequence of PEG's hydrophilicity, ease of end group modification, and low immunogenicity and antigenicity. ${ }^{26}$ Poly(propylene fumarate) (PPF), an unsaturated, degradable and hydrophobic polyester used in a number of medical applications such as controlled drug release, ${ }^{27,28}$ and tissue engineering ${ }^{29-37}$ has shown remarkable properties in the fabrication of medical devices and 3D tissue scaffolds using stereolithography (SLA), such as continuous digital light processing (cDLP) ${ }^{38-42}$ The chains can be photo-crosslinked through the alkenes to build reliable, high-fidelity structure from a UV sensitive liquid resin. ${ }^{43}, 44$ First, $\mathrm{PPF}_{\mathrm{n}}-b-\mathrm{PEG}_{\mathrm{m}}-b-\mathrm{PPF}_{\mathrm{n}}$ were synthesized with narrow molar mass distributions by using telechelic PEG chain as initiator for the copolymerization of maleic anhydride with propylene oxide. ${ }^{25}$ Then, aqueous printable resins were obtained by simply submerging a neat copolymer in water with a water-soluble photo-initiator. 3D printed hydrogels via cDLP were found to be compatible with MC3T3, NIH3T3, and Schwann cell lines demonstrating the potential of these materials in tissue engineering applications.

These amphiphilic $\mathrm{PPF}_{\mathrm{n}}-b-\mathrm{PEG}_{\mathrm{m}}-b-\mathrm{PPF}_{\mathrm{n}}$ hydrogels combine both physical interactions due to hydrophobicity of PPF blocks and covalent bonding. Because the key point driving the macroscopic properties of amphiphilic hydrogels is the phase separation in water, to further exploit 
their applications, their structures have been investigated by differential scanning calorimetry, in situ diffuse reflectance infrared spectroscopy (DRIFTS-IR) and small-angle neutron scattering to be correlated with their mechanical properties and degradation behavior.

\section{Experimental section}

\section{Materials}

All reagents were purchased from Sigma-Aldrich (St. Louis, MO, USA). All solvents were purchased from Fisher Scientific (Hampton, NH, USA) and dried using an Innovative Technology Inc. (Newburyport, MA, USA) Pure Solv MD-3 solvent purification system. $\operatorname{Mg}(\mathrm{BHT})_{2}(\mathrm{THF})_{2}$ was synthesized as reported previously. ${ }^{45}$ Poly(ethylene glycol) diol starting materials (2.0 kDa and $4.0 \mathrm{kDa}$ named $\mathrm{PEG}_{45}$ and $\mathrm{PEG}_{91}$ respectively) were dried by azeotropic distillation according to methods described previously. ${ }^{25}$ Maleic anhydride was dried under vacuum over $\mathrm{P}_{2} \mathrm{O}_{5}$ for one week. Propylene oxide was dried over calcium hydride overnight prior to vacuum distillation. All other reagents were used as received.

\section{Characterization techniques}

Proton $\left({ }^{1} \mathrm{H} ; 500 \mathrm{MHz}\right)$ and Carbon $\left({ }^{13} \mathrm{C} ; 125 \mathrm{MHz}\right)$ NMR experiments were performed in $\mathrm{D}_{2} \mathrm{O}$ or $\mathrm{CDCl}_{3}$ at $25{ }^{\circ} \mathrm{C}$ using a Varian (Palo Alto, CA, USA) Mercury NMRS 500 spectrometer. All chemical shifts were recorded in parts per million (ppm) relative to the reference peak solvent at $\delta$ $=4.80 \mathrm{ppm}$ for $\mathrm{D}_{2} \mathrm{O}$ and $\delta=7.26 \mathrm{ppm}$ for $\mathrm{CDCl}_{3}$. The relative number-average molar masses $\left(\overline{M_{n}}\right)$ and the molar mass distributions $\left(\bigoplus_{\mathrm{m}}\right)$ of the copolymers were determined by size exclusion chromatography (SEC) on a TOSOH (Grove City, OH, USA) EcoSEC HLC-8320GPC with 
TSKgel GMHHR-M columns in series. A refractive index detector (RI) and tetrahydrofuran (THF) was used as the eluent flowing at $1.0 \mathrm{~mL} \cdot \mathrm{min}^{-1}$. The sample concentrations were $10 \mathrm{mg} \cdot \mathrm{mL}^{-1}$. Relative $\overline{M_{n}}$ were calculated using a calibration curve determined from NIST-traceable polystyrene standards. Differential scanning calorimetry (DSC) was performed on uncured resins and hydrogels using a DSC-TA Discovery DSC250 (New Castle, DE, USA) scanning a temperature range from -50 to $120^{\circ} \mathrm{C}$ with heating and cooling ramps of $10^{\circ} \mathrm{C} \cdot \mathrm{min}^{-1}$. The crystallization and melting peaks were referred as the crystallization transition temperature $\left(T_{\mathrm{c}}\right)$ and the melting temperature $\left(T_{\mathrm{m}}\right)$, both determined at the peak transition.

The photocrosslinking reaction was studied over time during the UV curing process by in situ diffuse reflectance infrared Fourier transform spectroscopy (DRIFTS). A FTIR spectrometer equipped with an MCT detector Nicolet 6700 from Thermo Fisher Scientific (Waltham, MA, USA) and coupled with a diffuse reflectance infrared Fourier transform spectroscopy (DRIFTS) cell was used. A Hg lamp was used as a UV light source (Oriel 68810) with an intensity set to 50 $\mathrm{mW} \cdot \mathrm{cm}^{-2}$. An aliquot $(5 \mu \mathrm{L})$ of each $\mathrm{PPF}_{\mathrm{n}}-b-\mathrm{PEG}_{\mathrm{m}}-b-\mathrm{PPF}_{\mathrm{n}}$ suspension were placed in a metal sample holder with a diameter of $0.9 \mathrm{~cm}$ and depth of $0.4 \mathrm{~cm}$. The disk was placed in a DRIFTS cell and left open to ambient atmospheric conditions. The UV light was turned on after one minute and turned off after 10 min of curing. Each IR absorbance spectrum corresponds to four co-added scans with a resolution of $4 \mathrm{~cm}^{-1}$. Each in situ $\mathrm{UV}$ curing study was performed in triplicate. Relative alkene conversion $\mathrm{X}_{\mathrm{C}=\mathrm{C}}$ was determined overtime using OMNIC Software: the signal height at $v=$ $1646 \mathrm{~cm}^{-1}$ corresponding to the alkene $\mathrm{C}=\mathrm{C}$ stretching was normalized to the reference signal height at $v=1118 \mathrm{~cm}^{-1}$ which corresponds to $\mathrm{C}-\mathrm{O}$ stretching. ${ }^{46}$ The baseline used for the peak height was in the range $1800-1550 \mathrm{~cm}^{-1}$. Consequently, the following equation 1 was used: 


$$
\mathrm{X}_{C=C}=\frac{\frac{H_{1646, t_{0}}}{H_{1118, t_{0}}}-\frac{H_{1646, t}}{H_{1118, t}}}{\frac{H_{1646, t_{0}}}{H_{1118, t_{0}}}}
$$

Equation 1

The diameters and heights of 3D printed cylindrical hydrogels swollen in water for $48 \mathrm{~h}$ were measured with a digital caliper (Marathon, Vaughan, Ontario, Canada) with an accuracy of 0.01 mm.

The mechanical properties were measured by compression tests using an Instron 5543 universal testing machine (Norwood, MA, USA) at ambient temperature, with a strain rate of 0.1 $(\mathrm{mm} / \mathrm{mm}) / \mathrm{min}$. Force and displacement were zeroed prior to compression, with the top plate slightly above the surface of the sample. Each test was stopped manually when the samples were fractured to compression. The compressive moduli were obtained from the slope of the initial region of the stress-strain curve, by linear fitting the data from $0-5 \%$ strain. The compressive strength and fracture strain were defined respectively as the stress and strain at the point where the hydrogels fractured during a compressive test. Five samples were tested for each sample group (n $=5)$ and data were presented as means \pm standard deviations.

As microscopic image analyses have difficulties in keeping the gel structure intact during sample preparation, small-angle neutron scattering (SANS) experiments were performed to probe the nanostructure of crosslinked triblock copolymers in $\mathrm{D}_{2} \mathrm{O}$ (to enhance the scattering contrast between the polymer network and the solvent) at the National Institute of Standards (NIST) Center for Neutron Research (NCNR). Measurements were performed on the NGB-30 m SANS line with a neutron wavelength of $6.27 \AA$ at detector distances of $1.3,4$, and $13.2 \mathrm{~m}$, covering a scattering vector $q(q=(4 \pi / \lambda) \sin (\theta / 2))$ range of $0.004-0.4 \AA^{-1}$. The samples were loaded between two quartz slides with a $2 \mathrm{~mm}$ optical path length and the scattering for each sample was measured for $15 \mathrm{~min}$ at ambient temperature. All data were reduced using the Igor Pro NIST Reduction macros. 
Analysis of the scattering intensity aims at obtaining the characteristic sizes and the shape (represented by the form factor $\mathrm{P}(\mathrm{q})$ ), and the interactions (represented by the structure factor $\mathrm{S}(\mathrm{q})$ ). Classical expression of the scattering intensity per unit volume of particles is (Equation 2):

$$
\mathrm{I}(\mathrm{q})=\mathrm{n} \Delta \rho^{2} \mathrm{~V}_{\text {part }}^{2} \mathrm{P}(\mathrm{q}) \mathrm{S}(\mathrm{q})
$$

where $\mathrm{n}$ is the number density of particles, $\Delta \rho$ is the difference in the scattering length density between the scattering species and the solvent, and $\mathrm{V}_{\text {part. }}$ is the volume of scattering domains. The form factor describes the structure of domains and fulfills $\mathrm{P}(\mathrm{q} \rightarrow 0)=1$ while the structure factor describes the interaction between scattering domains.

The data were fitted using models available in the SaSview software (http://www.sasview.org). Guinier analyses were done by linearizing the data in the Guinier regime (plateau), plotting it as $\ln (\mathrm{I})$ versus $\mathrm{q}^{2} \cdot{ }^{47}$ The radius of gyration $\mathrm{R}_{\mathrm{g}}$ can be obtained by fitting the following model (Equation 3):

$$
\mathrm{I}(\mathrm{q})=\mathrm{I}(0) \exp \left(-\mathrm{R}_{\mathrm{g}} \mathrm{q}^{2} / 3\right)
$$

Equation 3

The Guinier-Porod model describes a generalized Guinier/power law object. This is an empirical model used to determine the size and dimensionality of scattering objects of diverse shapes, including asymmetric objects such as rods or platelets and intermediate shapes between spheres and rods or between rods and platelets. ${ }^{48}$ The scattering intensity is given by two contributions:

$$
I(q)= \begin{cases}\frac{G}{q^{d i m}} \exp \left(\frac{-q^{2} g^{2}}{3-d i m}\right) & \mathrm{q} \leq \mathrm{q}_{1} \\ D / \mathrm{q}^{\mathrm{m}} & \mathrm{q} \geq \mathrm{q}_{1}\end{cases}
$$


$\mathrm{I}(\mathrm{q})$ is the scattered intensity, $\mathrm{q}$ is the scattering variable, $\mathrm{R}_{\mathrm{g}}$ is the radius of gyration, $\mathrm{m}$ is the Porod exponent, and $\mathbf{G}$ and $\mathbf{D}$ are respectively the Guinier and Porod scale factors. With the requirement that the values of the Guinier and Porod terms and their slopes (derivatives) be continuous at a value $\mathrm{q}_{1}$, the following relationships (Equation 5) are obtained with the Guinier form used for $\mathrm{q} \leq \mathrm{q}_{1}$ and the Porod form used for $\mathrm{q} \geq \mathrm{q}_{1}$. The two forms are never used concurrently.

$$
\begin{gathered}
\mathrm{q}_{1}=\frac{1}{R_{g}}\left(\frac{3 m}{2}\right)^{1 / 2} \\
\mathrm{D}=\mathrm{G} \exp \left(\frac{-q_{1}^{2} R_{g}{ }^{2}}{3}\right) q_{1}{ }^{m}=\mathrm{G} \exp \left(\frac{-m}{2}\right)\left(\frac{3 m}{2}\right)^{1 / 2} \frac{1}{R_{g}{ }^{m}}
\end{gathered}
$$

For three-dimensional globular objects (such as spheres), $\operatorname{dim}=0$, for rods $\operatorname{dim}=1$ and for lamellae (or platelets) dim $=2$. A dimensionality parameter (3-dim) is defined.

The Guinier model can be applied in a narrow $\mathrm{q}$ range and is defined by the $\mathrm{R}_{\mathrm{g}}$. In hierarchical structures, such as hydrogels, at low q, the next larger structural level interferes, and at higher q, the Porod law regime obscures the operating range of the Guinier model. Indeed, to apply the power-law equation, at least one or two q decades in which the power-law scaling can be clearly observed are necessary. Consequently, it is difficult to apply both Guinier model and the power-law, especially in overlapping regimes. For these reasons, there was a need to define a scattering equation including both the Guinier model and the Porod-law in a non-exclusive manner over a wild range of scattering vector $\mathrm{q}$ and able to describe the combination of scattering functions from local structural levels to hierarchical structures such as those observed in polymer gels. This model developed by Beaucage (Equation 6), uses an empirical exponential/power-law fit method unified at multiple levels. ${ }^{49,}, 50$ 


$$
\begin{gathered}
\mathrm{I}(\mathrm{q})=\text { background }+\sum_{i=1}^{N}\left[G_{i} \exp \left(\frac{-q^{2} R_{g i}^{2}}{3}\right)+B_{i} \exp \left(\frac{-q^{2} R_{g(i+1)}^{2}}{3}\right)\left(\frac{1}{q_{i}^{*}}\right)^{P_{i}}\right] \quad \text { Equation } 6 \\
\text { with } q_{i}^{*}=q\left[\operatorname{erf}\left(\frac{q R_{g i}}{\sqrt{6}}\right)\right]^{-3}
\end{gathered}
$$

Here, two functions are included so two levels can be used. In addition, a 0 level has been added which calculates $I(q)=s c a l e / q+$ background. For each level, the four parameters $G i, R_{g i}, B_{i}$ and $P_{i}$ must be determined. Beaucage has an additional factor $\mathbf{k}$ in the definition of $\mathbf{q}_{\mathbf{i}}^{*}$ which is ignored here. The model works best for mass fractal systems characterized by Porod exponents from 5/3 to 3 and is particularly adapted for fractal analysis. It is a suitable method for the description of hydrogels because they are self-similar in certain length scales.

Synthesis of poly(propylene maleate-block-ethylene glycol-block-propylene maleate) (PPMn-b-

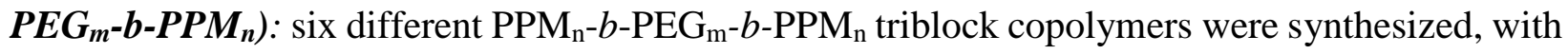
$m=45$ or 91 , the degree of polymerization $\left(\mathrm{DP}_{\mathrm{n}}\right)$ for the PEG block, and $\mathrm{n}=3,7$ or 12 , the $\mathrm{DP}_{\mathrm{n}}$ for each PPM block. As an example, for the synthesis of $\mathrm{PPM}_{7}-b-\mathrm{PEG}_{45}-b-\mathrm{PPM}_{7}$, dry $\mathrm{PEG}_{45}$-diol $(2.0 \mathrm{kDa}, 40.000 \mathrm{~g}, 0.02 \mathrm{~mol}), \mathrm{Mg}(\mathrm{BHT})_{2}(\mathrm{THF})_{2}$ catalyst (2.430 g, $0.004 \mathrm{~mol}, 0.20$ eq.), propylene oxide $(17.42 \mathrm{~g}, 20.50 \mathrm{~mL}, 0.30 \mathrm{~mol})$ and maleic anhydride $(29.42 \mathrm{~g}, 0.30 \mathrm{~mol})$ were dissolved in $160 \mathrm{~mL}$ of anhydrous toluene into a $250 \mathrm{~mL}$ round-bottom flask. The copolymerization was conducted at $100{ }^{\circ} \mathrm{C}$ under inert atmosphere for $48 \mathrm{~h}$. The resultant triblock copolymer was recovered by precipitation in hexanes at $40{ }^{\circ} \mathrm{C}$ and dried under vacuum. ${ }^{1} \mathrm{H} \mathrm{NMR}(500 \mathrm{MHz}, 303$ $\left.\mathrm{K}, \mathrm{CDCl}_{3}\right): \delta(\mathrm{ppm})=6.28-6.24(\mathrm{t}, \mathrm{OC}(=\mathrm{O}) \mathrm{CH}=\mathrm{CHC}(=\mathrm{O}) \mathrm{O}), 5.30-5.20\left(\mathrm{~m}, \mathrm{CH}_{2} \mathrm{CH}\left(\mathrm{CH}_{3}\right) \mathrm{O}\right)$, 4.29-4.21 (m, $\left.\mathrm{CH}_{2} \mathrm{CH}\left(\mathrm{CH}_{3}\right) \mathrm{O}\right), 3.64\left(\mathrm{~m}, \mathrm{OCH}_{2} \mathrm{CH}_{2} \mathrm{O}\right)$, and 1.33-1.31 (m, $\mathrm{CH}_{2} \mathrm{CH}\left(\mathrm{CH}_{3}\right) \mathrm{O}$.

Isomerization of (PPMn-b-PEG $\left.G_{m}-b-P P M_{n}\right)$ into poly(propylene fumarate-block-ethylene glycol-

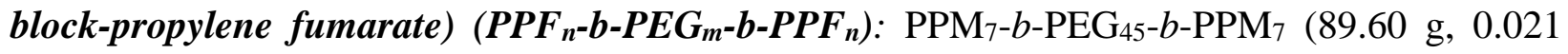


mol, 0.30 mol of olefin) was dissolved in chloroform $(150 \mathrm{~mL})$. Diethylamine $(3.30 \mathrm{~g}, 4.65 \mathrm{~mL}$, $0.045 \mathrm{~mol}, 0.15 \mathrm{~mol}$. eq. olefin) was added to the solution and the solution was heated to reflux for $24 \mathrm{~h}$ under a nitrogen atmosphere. After cooling to room temperature, the organic solution was washed with $1 \mathrm{M}$ sodium phosphate solution $(500 \mathrm{~mL}, \mathrm{pH}=6)$ and the polymer recovered by drying under vacuum. ${ }^{1} \mathrm{H}$ NMR $\left(500 \mathrm{MHz}, 303 \mathrm{~K}, \mathrm{CDCl}_{3}\right): \delta(\mathrm{ppm})=6.88-6.82(\mathrm{~m}$, $\mathrm{OC}(=\mathrm{O}) \mathrm{CH}=\mathrm{CH}(=\mathrm{O}) \mathrm{O})$, 5.35-5.25 $\left(\mathrm{m}, \mathrm{CH}_{2} \mathrm{CH}\left(\mathrm{CH}_{3}\right) \mathrm{O}\right), 4.43-4.18\left(\mathrm{~m}, \mathrm{CH}_{2} \mathrm{CH}\left(\mathrm{CH}_{3}\right) \mathrm{O}\right), 3.64(\mathrm{~m}$, $\left.\mathrm{OCH}_{2} \mathrm{CH}_{2} \mathrm{O}\right), 3.38\left(\mathrm{~s}, \mathrm{H}_{3} \mathrm{COCH}_{2} \mathrm{CH}_{2} \mathrm{O}\right)$ and $1.36-1.34\left(\mathrm{~m}, \mathrm{CH}_{2} \mathrm{CH}\left(\mathrm{CH}_{3}\right) \mathrm{O}\right)$.

Synthesis of lithium phenyl-2,4,6-trimethylbenzoylphosphinate (LAP): in a nitrogen filled twonecked $500 \mathrm{~mL}$ round bottom flask, $10.7 \mathrm{~g}$ of 2,4,6-trimethylbenzoylchloride ( $0.06 \mathrm{~mol})$ were added to $10 \mathrm{~g}$ of dimethylphenylphosphonite $(0.06 \mathrm{~mol}, 1 \mathrm{eq})$. The reaction was stirred at ambient temperature for $18 \mathrm{~h}$ and $20.13 \mathrm{~g}$ of $\mathrm{LiBr}(0.23 \mathrm{~mol}, 4 \mathrm{eq})$ in $125 \mathrm{~mL}$ of 2-butanone were added. The reaction was then heated to $50{ }^{\circ} \mathrm{C}$ for 10 min during which a white precipitate formed, followed by cooling for $3 \mathrm{~h}$ to ambient temperature. The precipitate was washed in a Büchner funnel with $300 \mathrm{~mL}$ of 2-butanone and dried under vacuum overnight. (13.22 g, $77 \%$ yield). ${ }^{1} \mathrm{H}$ NMR $\left(500 \mathrm{MHz}, 303 \mathrm{~K}, \mathrm{D}_{2} \mathrm{O}\right): \delta(\mathrm{ppm})=7.82-7.78($ tot, $2 \mathrm{H}), 7.67-7.64($ tot, $1 \mathrm{H}), 7.57-7.54(\mathrm{~m}$, 2H), $6.98(\mathrm{~s}, 2 \mathrm{H}), 2.33(\mathrm{~s}, 3 \mathrm{H})$, and $2.11(\mathrm{~s}, 6 \mathrm{H})$.

Continuous digital light processing (cDLP) additive manufacturing: Aqueous suspensions of $\mathrm{PPF}_{\mathrm{n}}-b-\mathrm{PEG}_{\mathrm{m}}-b-\mathrm{PPF}_{\mathrm{n}}$ triblock copolymer were prepared at $20 \mathrm{wt} . \%$ in deionized water with a 1:5 molar ratio of LAP:alkene. The mixtures were stirred magnetically at $50{ }^{\circ} \mathrm{C}$ overnight to ensure homogeneous mixing. Hydrogels were printed on an EnvisionTEC (Dearborn, MI, USA) Micro Plus Hi-Res 3D Printer, which uses a $405 \mathrm{~nm}$ UV projector with a layer resolution of $50 \mu \mathrm{m}$. Before printing, a curing test was performed for each resin to determine the exposure time/layer of hydrogel: drops of solution were crosslinked with different exposure times and the thickness of 
the resulting cured films was measured with a caliper. Optimal exposure time to obtain a layer of $50 \mu \mathrm{m}$ was obtained from linear regression and defined to be in range of 20-180 seconds depending on the formulation. 3D cylindrical models (with $6 \mathrm{~mm}$ diameter and $3 \mathrm{~mm}$ height) were designed using EnvisionTEC Perfactory software by scaling standard CAD files from ASTM standards. After each printing job, uncured resin on printed hydrogels was washed out gently with deionized water. The hydrogels were then removed from the build plate using a razor blade before being placed on glass slides and put into a UV chamber (EnvisionTec, $70 \mathrm{~W}, 55 \mathrm{~Hz}, \lambda_{\max }=400 \mathrm{~nm}$ ) for 20 min to further crosslinking. They were then reserved in capped vials to prevent dehydration and for further use.

Sol fraction measurements: the 3D printed hydrogels were frozen in liquid nitrogen and lyophilized. The lyophilized materials were weighed $\left(W_{1}\right)$ and placed individually in $10 \mathrm{~mL}$ of acetone overnight to remove the uncrosslinked copolymer (sol). Washing was repeated twice to ensure complete removal. Hydrogels were lyophilized and weighed again $\left(W_{\mathrm{g}}\right)$. Four independent samples were assessed for each group $(n=4)$. The sol fraction was calculated by the following equation 7:

$$
\text { Sol Fraction }(\%)=\frac{W_{1}-W_{\mathrm{g}}}{W_{\mathrm{l}}} \times 100
$$

In vitro degradation study: The $3 \mathrm{D}$ printed hydrogels $(\mathrm{n}=210)$ were placed individually in 10 $\mathrm{mL}$ of acetone overnight to extract the sol, the acetone was removed, the hydrogels dried under vacuum and placed in $10 \mathrm{~mL}$ of phosphate buffer saline (PBS, $\mathrm{pH}=7.4$ ) in individual vials at $37^{\circ} \mathrm{C}$. The solutions were replaced with fresh PBS every four days. At each time point (days 2, 4, $6,8,16,24$, and 32), five samples were taken out for gravimetrical analysis $(n=5)$. The hydrogels were weighed in the swollen state $\left(W_{\mathrm{s}}\right)$, washed in deionized water, dried, and weighed again $\left(W_{\mathrm{d}}\right)$. 
Each sample was weighed in the swollen state $\left(W_{\mathrm{is}}\right)$ and the dried state $\left(W_{\mathrm{id}}\right)$ prior to degradation for reference. The normalized remaining mass for each sample was calculated by:

$$
\text { Remaining mass }(\%)=\frac{W_{\mathrm{id}}-W_{\mathrm{d}}}{W_{\mathrm{id}}} \times 100 \quad \text { Equation } 8
$$

Water content for each sample at each time point was calculated by:

$$
\text { Water Content }(\%)=\frac{W_{\mathrm{s}}-W_{\mathrm{d}}}{W_{\mathrm{d}}} \times 100 \quad \text { Equation } 9
$$

The swelling ratio of the hydrogels by weight was defined by:

$$
\text { Swelling Ratio }(\%)=\frac{W_{\mathrm{s}}}{W_{\mathrm{d}}} \times 100 \quad \text { Equation } 10
$$

\section{Results and discussion}

Poly(propylene fumarate $)_{\mathrm{n}}$-block-poly(ethylene glycol $)_{\mathrm{m}}$-block-poly(propylene fumarate $)_{\mathrm{n}}\left(\mathrm{PPF}_{\mathrm{n}^{-}}\right.$ $\left.b-\mathrm{PEG}_{\mathrm{m}}-b-\mathrm{PPF}_{\mathrm{n}}\right) \mathrm{ABA}$ triblock copolymers were synthesized by ring-opening copolymerization of maleic anhydride and propylene oxide initiated by PEG-diol as described previously. ${ }^{25}$ The number average molar mass $\left(\overline{M_{n}}\right)$ of PPF blocks and consequently the total $\overline{M_{n}}$ were deduced from MAn conversion from ${ }^{1} \mathrm{H}$ NMR spectra of crude samples by comparing the monomer proton resonance $(\delta=7.01 \mathrm{ppm}, 2 \mathrm{H})$ to the corresponding polymer proton resonance $(\delta=6.27 \mathrm{ppm})$. The monomer conversion of propylene oxide (PO) was not determined due to the low vapor pressure and boiling point of the PO leading to unreliable integrations assessed by ${ }^{1} \mathrm{H}$ NMR spectroscopy. Six copolymers with varying PEG and PPF block lengths corresponding to a large range of hydrophilic mass ratios $(f)$ were synthesized, three copolymers with a hydrophilic PEG middle block of $2.0 \mathrm{kDa}: \mathrm{PPF}_{3}-b-\mathrm{PEG}_{45}-b-\mathrm{PPF}_{3}(f=68 \%), \mathrm{PPF}_{7}-b-\mathrm{PEG}_{45}-b-\mathrm{PPF}_{7}(f=48 \%)$, $\mathrm{PPF}_{12}-b-\mathrm{PEG}_{45}-b-\mathrm{PPF}_{12}(f=35 \%)$ and three copolymers with a hydrophilic PEG middle block of 
4.0 kDa: $\mathrm{PPF}_{3}-b-\mathrm{PEG}_{91}-b-\mathrm{PPF}_{3}(f=81 \%), \mathrm{PPF}_{7}-b-\mathrm{PEG}_{91}-b-\mathrm{PPF}_{7}(f=65 \%), \mathrm{PPF}_{12}-b-\mathrm{PEG}_{91}-b-$ $\operatorname{PPF}_{12}(f=52 \%)$ (Table 1).

Table 1. Molecular characteristics of $\mathrm{PPF}_{\mathrm{n}}-b-\mathrm{PEG}_{\mathrm{m}}-b-\mathrm{PPF}_{\mathrm{n}}$ triblock copolymers.

\begin{tabular}{|c|c|c|c|c|c|c|c|c|}
\hline Entry & $\begin{array}{c}\text { PEG } \overline{M_{n}} \\
(\mathrm{kDa})\end{array}$ & $\begin{array}{c}\text { Target DP } \\
\text { PPFa }\end{array}$ & $\begin{array}{c}\text { MAn conversion }^{b} \\
(\%)\end{array}$ & 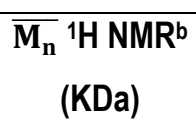 & $\begin{array}{c}\overline{\mathbf{M}_{\mathbf{n}}} \text { SEC } \\
(\mathrm{KDa})\end{array}$ & $\begin{array}{c}\overline{\bar{M}_{w}} \text { SEC } \\
(\mathrm{KDa})\end{array}$ & $\bigoplus_{M^{c}}$ & $\begin{array}{c}f \\
(\%)^{d}\end{array}$ \\
\hline 1 & & 6 & 95 & 2.9 & 0.5 & 0.5 & 1.12 & 68 \\
\hline 2 & 2.0 & 15 & 95 & 4.2 & 3.6 & 4.9 & 1.49 & 48 \\
\hline 3 & & 25 & 97 & 5.7 & 4.6 & 7.5 & 1.61 & 35 \\
\hline 4 & & 6 & 91 & 4.9 & 4.3 & 7.2 & 1.65 & 81 \\
\hline 5 & 4.0 & 15 & 99 & 6.3 & 6.7 & 10.0 & 1.51 & 65 \\
\hline 6 & & 25 & 94 & 7.7 & 4.3 & 8.3 & 1.92 & 52 \\
\hline
\end{tabular}

$\bar{a}$ Based on an initiator-to-monomer ratio, ${ }^{\mathrm{b} 1} \mathrm{H}$ NMR in $\mathrm{CDCl}_{3},{ }^{\mathrm{c}} \mathrm{SEC}$ in THF, RI detector, PS standard, ${ }^{\mathrm{d}}$ hydrophilic weight fraction $f=\mathrm{PEG} \overline{M_{n}} /$ total $\overline{M_{n}}$ based on ${ }^{1} \mathrm{H}$ NMR.

As previously reported ${ }^{25} \mathrm{ABA}$ triblock copolymers with a PEG middle block having a $\overline{M_{n}}$ of 2.0 $\mathrm{kDa}$ and more were suspended homogeneously in water, allowing for the formation of photochemically 3D printed crosslinked hydrogels in the presence of a water-soluble lithium phenyl-2,4,6-trimethylbenzoylphosphinate (LAP) photoinitiator. Moreover, we showed that the swelling ratio decreased as the PPF block length increased.

As a consequence, the present work focuses on the effect of PEG and PPF block lengths on the nanoscale ordering within the hydrogel due to amphiphilicity of the various copolymers and their resulting mechanical and degradation properties. The macroscopic mechanical properties were 
investigated via compression tests and the structures of these 3D printed hydrogels have been investigated by classical characterization methods as differential scanning calorimetry, and by in situ DRIFTS-IR and small-angle neutron scattering.

First, the thermal properties of $\mathrm{PPF}_{\mathrm{n}}-b-\mathrm{PEG}_{\mathrm{m}}-b-\mathrm{PPF}_{\mathrm{n}}$ copolymers in water at $20 \mathrm{wt}$. $\%$ before 3D printing and of chemically crosslinked hydrogels were investigated by DSC. The thermograms that were obtained are presented in Figure 1. In water, the thermal properties were dominated by the melting of PEG, which lies between 30 and $38^{\circ} \mathrm{C}$ for $\mathrm{PEG}_{45}$ and between 45 and $52{ }^{\circ} \mathrm{C}$ for $\mathrm{PEG}_{91}$ (Figures 1A and 1B). In suspension DSC traces showed an exothermic transition peak attributed to the crystallization of the $\mathrm{PEG}$ block when linked to $\mathrm{PPF}_{7}$ and $\mathrm{PPF}_{12}$, highlighting the role of the hydrophobic PPF block length on the capacity of these triblock to organize in water. The large melting transitions of PEG crystals occluded the appearance of the $T_{\mathrm{g}}$ of the amorphous PPF blocks usually observed around -6 and $12^{\circ} \mathrm{C}$ for oligomeric PPF. ${ }^{51}$ For the covalently crosslinked hydrogels (Figures 1C and 1D), the DSC traces showed a clear difference in the PEG crystallization behavior, indeed, the crosslinking triggered a total disappearance of PEG crystallization peaks. Moreover, in these hydrogels, we observed a large decrease or a total disappearance of the melting peak $\left(\mathrm{T}_{\mathrm{m}}\right)$ for the longest PPF blocks, showing that the crosslinking hindered the crystallization of the PEG middle block due to entanglements and a lack of mobility. 

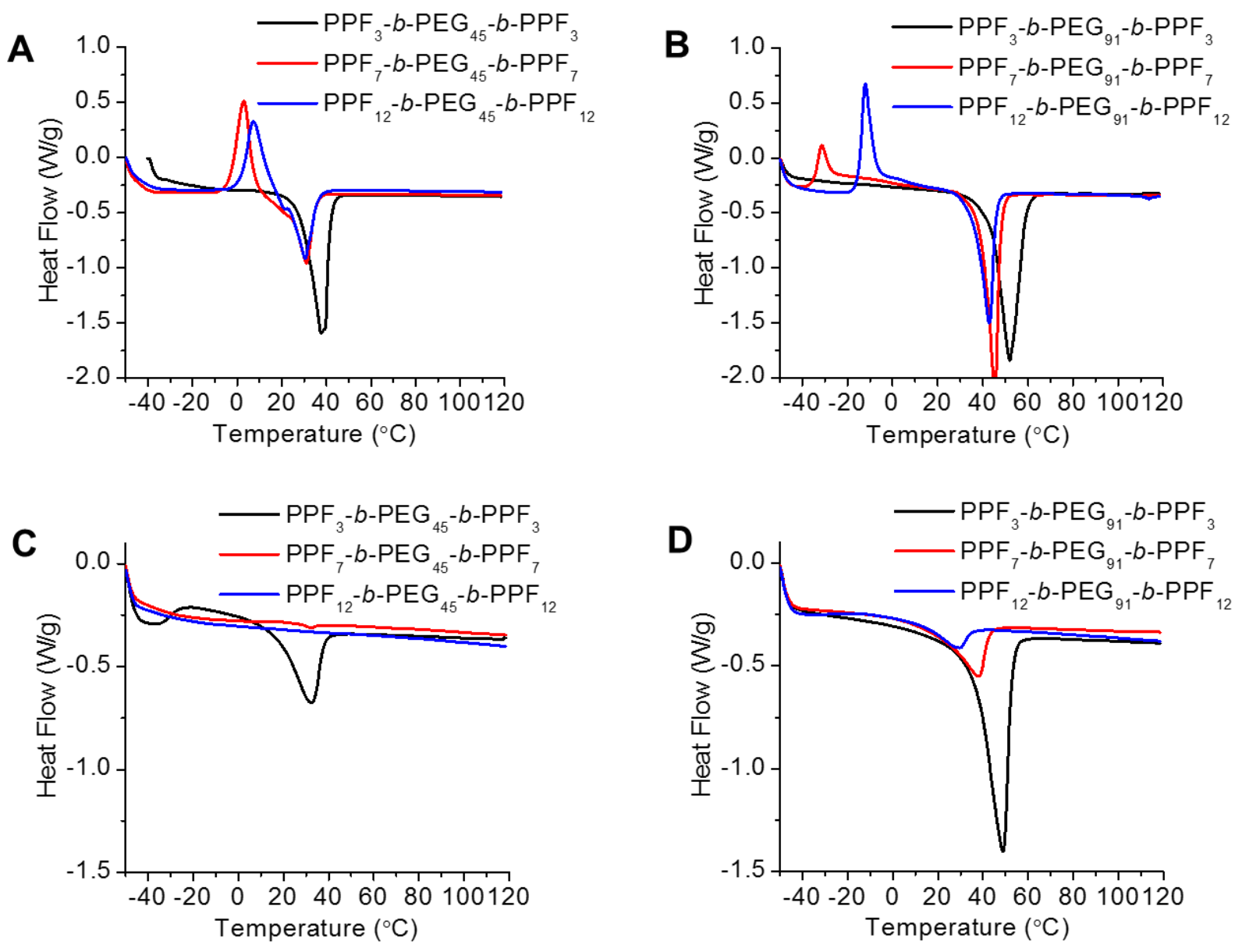

Figure 1. Differential scanning calorimetry (DSC) traces for $\mathrm{PPF}_{\mathrm{n}}-b-\mathrm{PEG}_{\mathrm{m}}-b-\mathrm{PPF}_{\mathrm{n}}$ triblock copolymers in water (20 wt.\%), with (A) $\mathrm{PEG}_{45}$ and (B) $\mathrm{PEG}_{91}$, and for 3D printed hydrogels with (C) $\mathrm{PEG}_{45}$ and (D) $\mathrm{PEG}_{91}$. Temperature scan rate was $10{ }^{\circ} \mathrm{C} \cdot \mathrm{min}^{-1}$.

In contrast to the mono- and end-functionalization crosslinking sites observed in many hydrogel systems, the unsaturated backbone of PPF offers many sites for possible crosslinking. The crosslinking density has been demonstrated in numerous examples to directly affect network mechanical properties. ${ }^{52}$ Therefore, as the PPF block length increases in $\mathrm{PPF}_{\mathrm{n}}-b-\mathrm{PEG}_{\mathrm{m}}-b-\mathrm{PPF}_{\mathrm{n}}$ copolymers, it is reasonable to expect differences with regard to intra- and interchain crosslinking and consequently in the mechanical properties of the hydrogel. To assess the amount of crosslinking for each copolymer, the change in the alkene stretch absorbance at $v=1646 \mathrm{~cm}^{-1}$ was 
monitored during the crosslinking reaction by in situ IR spectroscopy (Figure 2A). The double bond absorbance at $1646 \mathrm{~cm}^{-1}$ was plotted versus time in Figure 2B. Upon the exposure of UV light onto the uncrosslinked aqueous suspension, the signal intensity of $\mathrm{C}=\mathrm{C}$ stretching rapidly decreased, indicating the formation of the covalent network. The relative conversion of double bonds into single bonds for each triblock copolymer was calculated as the ratio between the peak height for $\mathrm{C}=\mathrm{C}$ to a constant reference peak (stretching at $1118 \mathrm{~cm}^{-1}$ ) as shown in Figure $2 \mathrm{C}$.
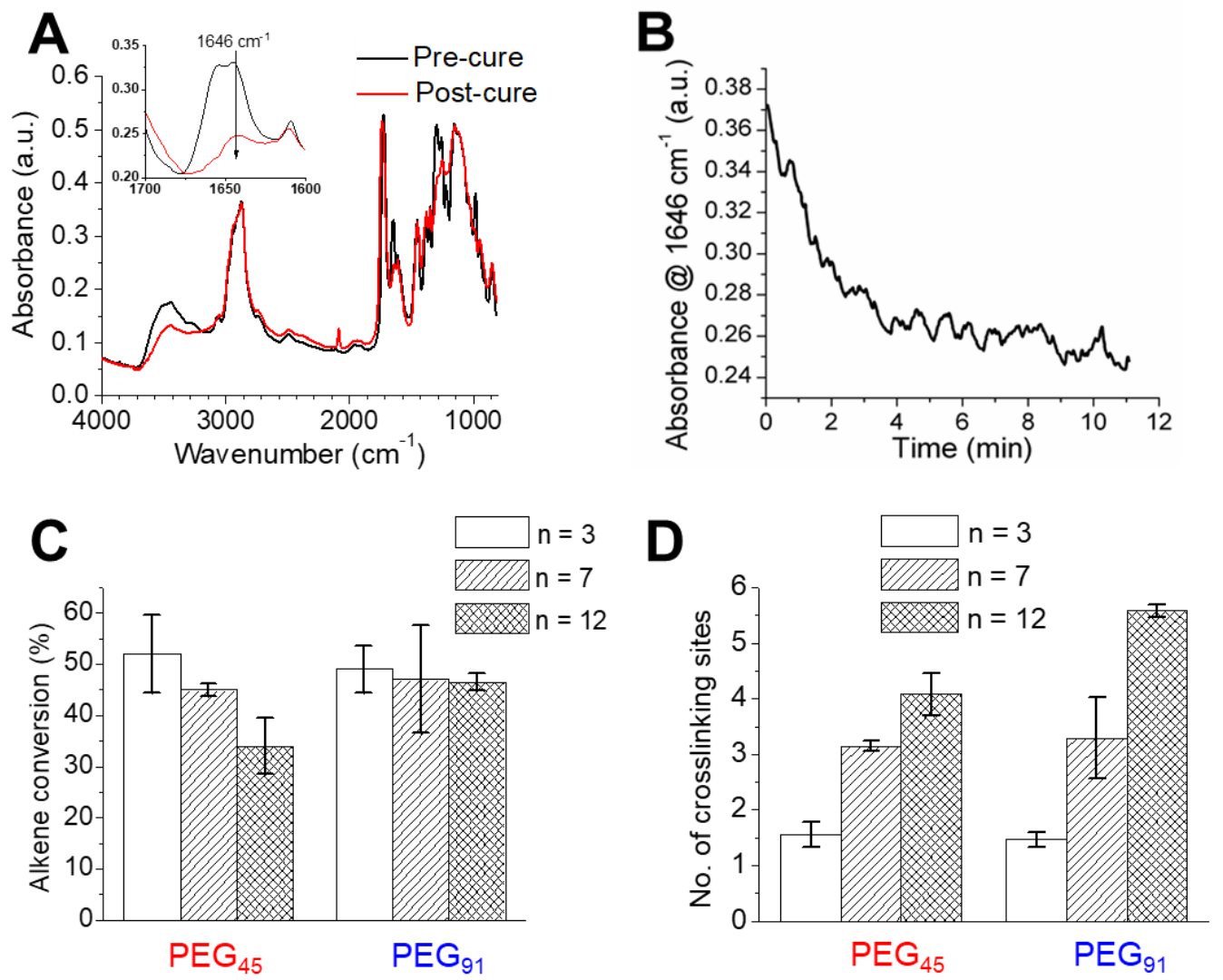

Figure 2. In situ DRIFTS-IR measurements of $\mathrm{PPF}_{\mathrm{n}}-b-\mathrm{PEG}_{\mathrm{m}}-b-\mathrm{PPF}_{\mathrm{n}}$ uncrosslinked suspensions and crosslinked hydrogels. (A) IR profile of $\mathrm{PPF}_{12}-b-\mathrm{PEG}_{45}-b-\mathrm{PPF}_{12}$ before (black line) and after photocrosslinking (red line). The double bond absorbance was seen to decrease after UV treatment (inset). (B) Evolution of double bond stretching absorbance at $1646 \mathrm{~cm}^{-1}$ over time during UV exposure. (C) Relative alkene conversion determined as a function of block length. (D) Number of crosslinking sites as a function of block length. 
For the $\mathrm{PEG}_{45}$-based series, the double bond conversion followed a decreasing trend as the PPF block increased, from $52 \pm 8 \%$ for $\mathrm{PPF}_{3}-b-\mathrm{PEG}_{45}-b-\mathrm{PPF}_{3}$ to $34 \pm 6 \%$ for $\mathrm{PPF}_{12}-b-\mathrm{PEG}_{45}-b-$ $\mathrm{PPF}_{12}$, indicating a higher crosslinking ratio for the shortest PPF block length. However, no significant difference in the double bond conversion was observed for the triblock copolymer series with a longer PEG $_{91}$ block, indeed, the values stayed in a short range, about $49-46 \%$, regardless of the PPF block. Nevertheless, in both cases, the absolute effective crosslinking site number significantly increased with the PPF block length, highlighting a particular high number of crosslinking sites for the $\mathrm{PPF}_{12}-b-\mathrm{PEG}_{91}-b-\mathrm{PPF}_{12}$, combining the longest PEG and PPF blocks. These results demonstrated the role of a long hydrophilic and flexible PEG middle block, favoring the crosslinking reaction and opened interrogations about how the block length controlled the related self-organization in water.

Because the key point driving the macroscopic properties amphiphilic networks is their phase separation, the mechanical response of gels depends on their structure at various length scales. Small-angle neutrons scattering (SANS) constitutes a remarkable technique capable of describing the self-assembly behavior of hydrophobic chain while taking into consideration specific defects through appropriate models. SANS was employed to gain better insight in the phase separation phenomenon and to probe quantitatively the nanoscopic structure in crosslinked hydrogels as a function of PEG and PPF block lengths (Figure 3). For clarity, scattered intensities of red and blue curves were multiplied by a power of 10 on the graph. The fitting parameters used are summarized in Table S1. 

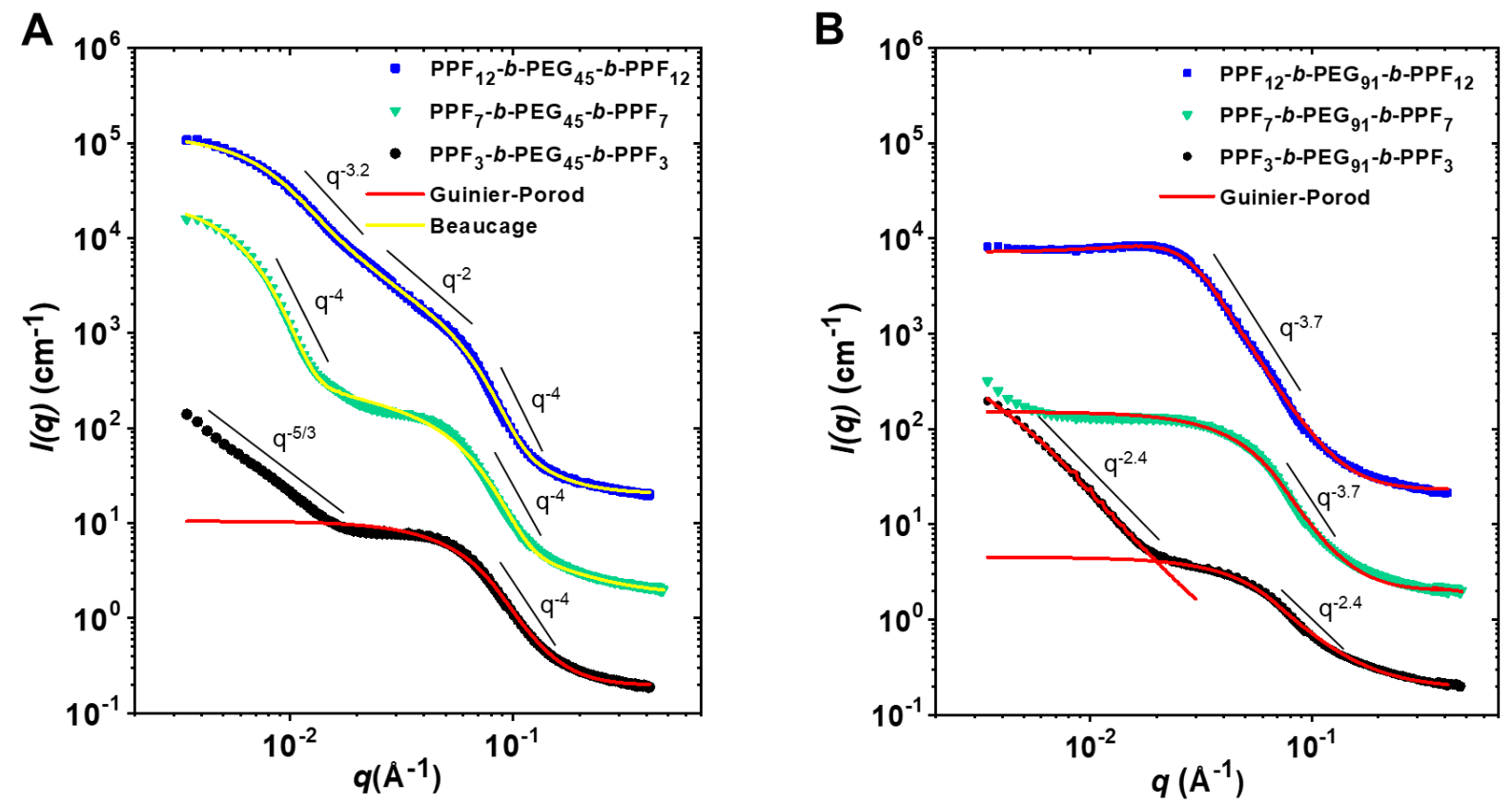

Figure 3. Small-angle neutron scattering of crosslinked hydrogels made of $\mathrm{PPF}_{\mathrm{n}}-b-\mathrm{PEG}_{\mathrm{m}}-b-\mathrm{PPF}_{\mathrm{n}}$ triblock copolymers in $\mathrm{D}_{2} \mathrm{O}\left(20\right.$ wt. \%) with $(\mathbf{A}) \mathrm{PEG}_{45}(2.0 \mathrm{kDa})$ and $(\mathbf{B}) \mathrm{PEG}_{91}(4.0 \mathrm{kDa})$ as hydrophilic middle block. The solid red lines are the fitting curves obtained by using the GuinierPorod model while the solid yellow lines were obtained from the unified Beaucage model.

From a general point of view, the SANS data obtained with these hydrogels are qualitatively very different within each series. On the Figure $\mathbf{3 A}$, the scattered intensity as a function of $\mathrm{q}$ for $\mathrm{PPF}_{3}-b-\mathrm{PEG}_{45}-b-\mathrm{PPF}_{3}$ showed an intermediate q value regime $\left(2.0 \times 10^{-2} \AA^{-1}<\mathrm{q}<1.5 \times 10^{-1} \AA^{-1}\right)$ with a variation in $\mathrm{q}^{-4}$ followed by a Guinier plateau that corresponds to a compact structure characterized by a sharp surface and a finite size approachable by SANS. At the lowest q values, the data showed a weaker variation in $\mathrm{q}^{-5 / 3}$ corresponding to large size clusters. This variation in $\mathrm{q}^{-5 / 3}$ is the signature of a diffusion-limited cluster aggregation (DLCA) process whereby particles, undergoing a random walk due to Brownian motion and a lack of repulsive forces, cluster together, forming aggregates of such particles. The first part of this curve, from the highest q values to the Guinier plateau was fitted using the Guinier-Porod model allowing to determine the radius of 
gyration $\mathrm{R}_{\mathrm{g}}=27.0 \AA$ (and $\mathrm{R}=34.9 \AA$ ) of the scattering spherical particles $(\operatorname{dim}=0)$. For PPF $-b$ $\mathrm{PEG}_{45}-b-\mathrm{PPF}_{7}$, the scattering curve could be divided into two distinct regimes separated by the socalled "knee point" at $\mathrm{q}_{\mathrm{c}} \approx 2 \cdot 10^{-2} \AA^{-1}$. The first regime $\left(\mathrm{q}>\mathrm{q}_{\mathrm{c}}\right)$ revealed discrete internal structures whereas scattering from large clusters dominated within the second regime $\left(\mathrm{q}<\mathrm{q}_{\mathrm{c}}\right)$. Both regimes showed variations in $\mathrm{q}^{-4}$, each followed by a Guinier plateau describing a well-defined hierarchical multiscale organization. This scattering is well described by the yellow line representing the best fit of the data using the Beaucage model with $\mathrm{R}_{\mathrm{g} 1}=32.8 \AA$ and $\mathrm{R}_{\mathrm{g} 2}=333.2 \AA$. The scattered intensity as a function of $\mathrm{q}$ for $\mathrm{PPF}_{12}-b-\mathrm{PEG}_{45}-b-\mathrm{PPF}_{12}$ showed a succession of different powerlaws: a variation in $\mathrm{q}^{-4}$ corresponding to a compact structure of sharp surface in a $1.5 .10^{-1}-7.10^{-2}$ $\AA^{-1} \mathrm{q}$ range, followed by an intermediate variation in $\mathrm{q}^{-2}$, a variation in $\mathrm{q}^{-3.2}$ and by the beginning of a Guinier plateau at the lowest q values. Thereby for this hydrogel, the scattering indicates dominating self-assembled structures bundles with fractal-like aggregation. The yellow fitting curve using the Beaucage model revealed $\mathrm{R}_{\mathrm{g} 1}=35.9 \AA$ and $\mathrm{R}_{\mathrm{g} 2}=215.4 \AA$.

The Figure 3B presents the scattering data and corresponding fits for crosslinked hydrogels based on triblock copolymers with a $\mathrm{PEG}_{91}$ middle block. For $\mathrm{PPF}_{3}-b-\mathrm{PEG}_{91}-b-\mathrm{PPF}_{3}$, the triblock copolymer with the highest hydrophilic weight ratios $(f=81 \%)$, the intermediate q value regime $\left(2.0 \times 10^{-2} \AA^{-1}<\mathrm{q}<1.5 \times 10^{-1} \AA^{-1}\right)$ is characterized by a variation in $\mathrm{q}^{-2.4}$, characterizing undefined aggregates $(\operatorname{dim}=0)$ with a weak interface, indicating that lower $f$ values are necessary to drive the formation of hydrophobic domains with sharp surface. Moreover, the scattering at the lower $\mathrm{q}$ range, in $\mathrm{q}^{-2.4}$, is well described by a Guinier-Porod model corresponding to rods $(\operatorname{dim}=1)$ with a reaction-limited cluster aggregation phenomenon (RLCA), in which a repulsive potential is in place with only a fraction of the occurring collisions is effective (as not all particles over-come the repulsive forces present). The scattered intensity as a function of $\mathrm{q}$ for $\mathrm{PPF}_{7}-b-\mathrm{PEG}_{91}-b-\mathrm{PPF}_{7}$ 
revealed a variation in $\mathrm{q}^{-4}$ followed by Guinier plateau corresponding to spherical aggregates of $\mathrm{R}_{\mathrm{g}}$ $=32.3 \AA$ and a slight intensity increase corresponding to a poorly aggregated structure. Finally, for $\mathrm{PPF}_{12}-b-\mathrm{PEG}_{91}-b-\mathrm{PPF}_{12}$, the triblock copolymer combining both relatively long PEG and PPF blocks, the data display a slight correlation peak at $\mathrm{q}=\mathrm{q}^{*}$ indicating that the nanoaggregates show a preferred separation distance $\xi=\frac{2 \pi}{q^{*}}$ due to repulsive effect The best fit was obtained using a Guinier-Porod model with a Percus-Yevick structure factor describing hard spheres of $R_{g}=60.6$ $\AA(\mathrm{R}=78.2 \AA)$ with $\xi=220.0 \AA$. The aggregation of colloidal particles is regulated by the balance between repulsive and attractive forces, or rather by the corresponding repulsive $\left(V_{R}\right)$ and attractive $\left(\mathrm{V}_{\mathrm{A}}\right)$ potentials. Therefore, the aggregation mechanism of the hydrogels can be conjectured from their resulting fractal structures. Moreover, sol fraction measurements (Figure 4) revealed that the hydrogels with longer hydrophobic PPF blocks tend to contain higher soluble portion in both series, which could be attributed to the favored formation of self-assembled nanostructures that do not incorporate into the network. In addition, hydrogels prepared from $\mathrm{PEG}_{91}$ had slightly less sol than those prepared from $\mathrm{PEG}_{45}$ with the same PPF DP. Consequently, short PPF blocks and relatively long PEG middle block are necessary to ensure interconnection between hydrophobic crosslinked domains. 


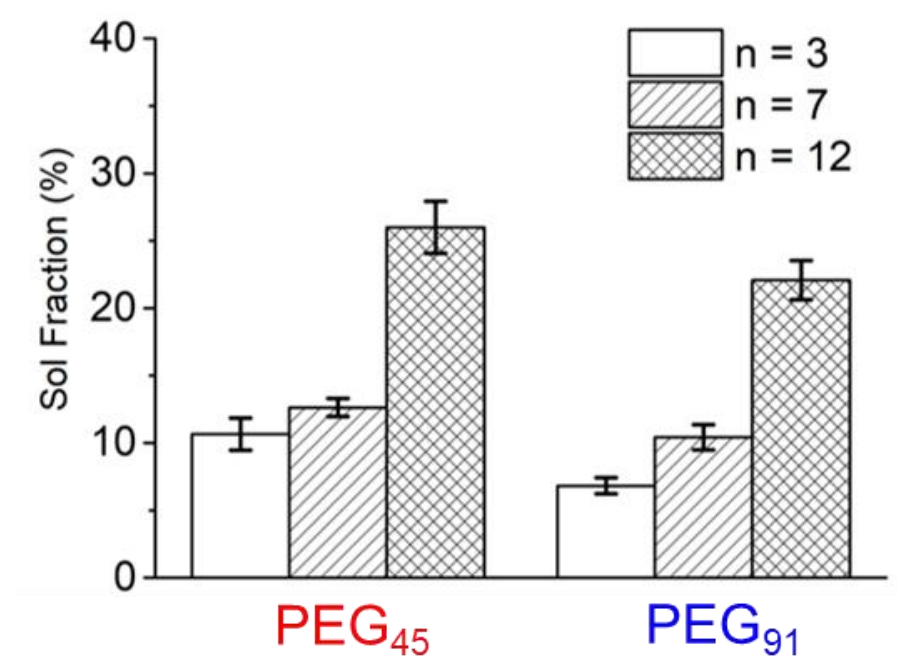

Figure 4. Sol fraction of $3 \mathrm{D}$ printed $\mathrm{PPF}_{\mathrm{n}}-b-\mathrm{PEG}_{\mathrm{m}}-b-\mathrm{PPF}_{\mathrm{n}}$ triblock copolymers hydrogels $(\mathrm{n}=3$, 7 and 12 , and $m=45$ and 91).

Consequently, a general representation of the internal structure of hydrogels made of $\mathrm{PPF}_{\mathrm{n}}-b$ $\mathrm{PEG}_{\mathrm{m}}-b-\mathrm{PPF}_{\mathrm{n}}$ ABA triblock copolymers is shown in Scheme 1. The results show that the aggregation mechanisms and the hydrogel nanostructures are mostly driven by the length of the PEG middle block. For short $\mathrm{PEG}_{45}$ middle block of $2.0 \mathrm{kDa}$, the hydrophobic interactions between the PPF blocks are stronger so the particles aggregate kinetically with no possible rearrangement, leading to a diffusion-limited aggregation. On the contrary, for longer PEG $_{91}$ middle block of 4.0 $\mathrm{kDa}$, the ordering is mainly conducted by repulsive forces, through a reaction-limited cluster aggregation phenomenon. Nevertheless, the length $\left(\mathrm{DP}_{\mathrm{n}}\right)$ of the crosslinkable PPF blocks controls the cohesion between crosslinked domains. 


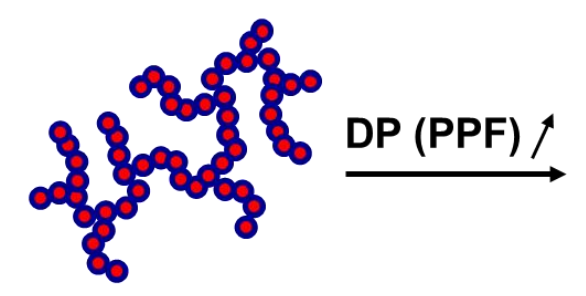

Cluster of particles

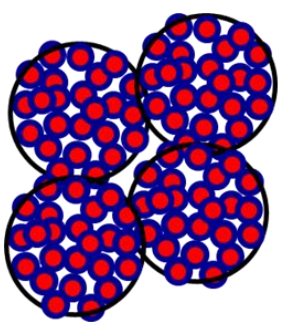

Aggregation of spherical clusters
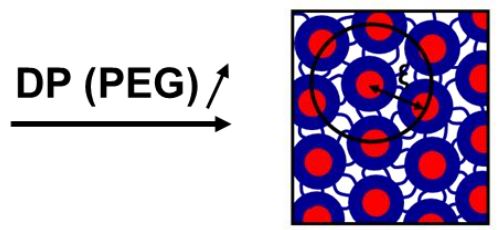

Organized clusters (preferred distance $\xi$ between particles)

Scheme 1. General representation of the internal structure of hydrogels based on $\mathrm{PPF}_{\mathrm{n}}-b-\mathrm{PEG}_{\mathrm{m}}-b$ $\mathrm{PPF}_{\mathrm{n}} \mathrm{ABA}$ triblock copolymers depending on the DP increase of each block (PPF (red) and PEG in (blue)).

To elucidate the link between the gel structures and their mechanical properties, uniaxial compressive tests were performed. The resulting stress-strain curves (Figure 5A) showed a fracture for all the swollen hydrogels. However, due to a better network flexibility, hydrogels containing the longest PEG middle block exhibited higher compression capacity than those containing the shortest PEG (Figure 5B). As reported in the literature for chemically crosslinked hydrogels, the increase in crosslink density usually results in higher modulus and strength, but the hydrogels become rigid and fragile. ${ }^{53}$ Interestingly, as presented in Figures 5 C and 5D, increasing DP of PPF blocks and consequently the number of crosslinked sites led to a fall in the resistance to breaking and compressive modulus in both copolymer series. On the contrary, the swollen PEG regions allow to building up the stress and similar hydrophilic weight fractions $f$ led to close compressive strength values. Moreover, the $\mathrm{PPF}_{12}-b-\mathrm{PEG}_{45}-b-\mathrm{PPF}_{12}$ hydrogel was shown to exhibit significantly lower compressive strength and compressive modulus than the other five formulations due to poor interconnection between PPF domains. The characteristic values of mechanical properties obtained from compressive tests are resumed in the Table 2. The water content increased when hydrophilic weight fraction $f$ increased but non-linearly. Moreover, in each 
series, short $\mathrm{PPF}_{3}$ blocks led to higher water contents while copolymers with $\mathrm{PPF}_{7}$ and $\mathrm{PPF}_{12}$ blocks showed similar water content values. However, the mechanical properties did not correlate clearly with the water content. These observations suggest differences in nanostructure into amphiphilic triblock copolymer hydrogels, and consequently into interconnections of PPF crosslinked domains, are responsible for maintaining high compressive modulus combining with high PEG content and relatively low crosslinking sites. Indeed, longer hydrophobic PPF blocks tend to decrease the mobility of the PEG block, to favor the formation of crosslinked nanostructures that do not incorporate into the network, decreasing the mechanical properties.
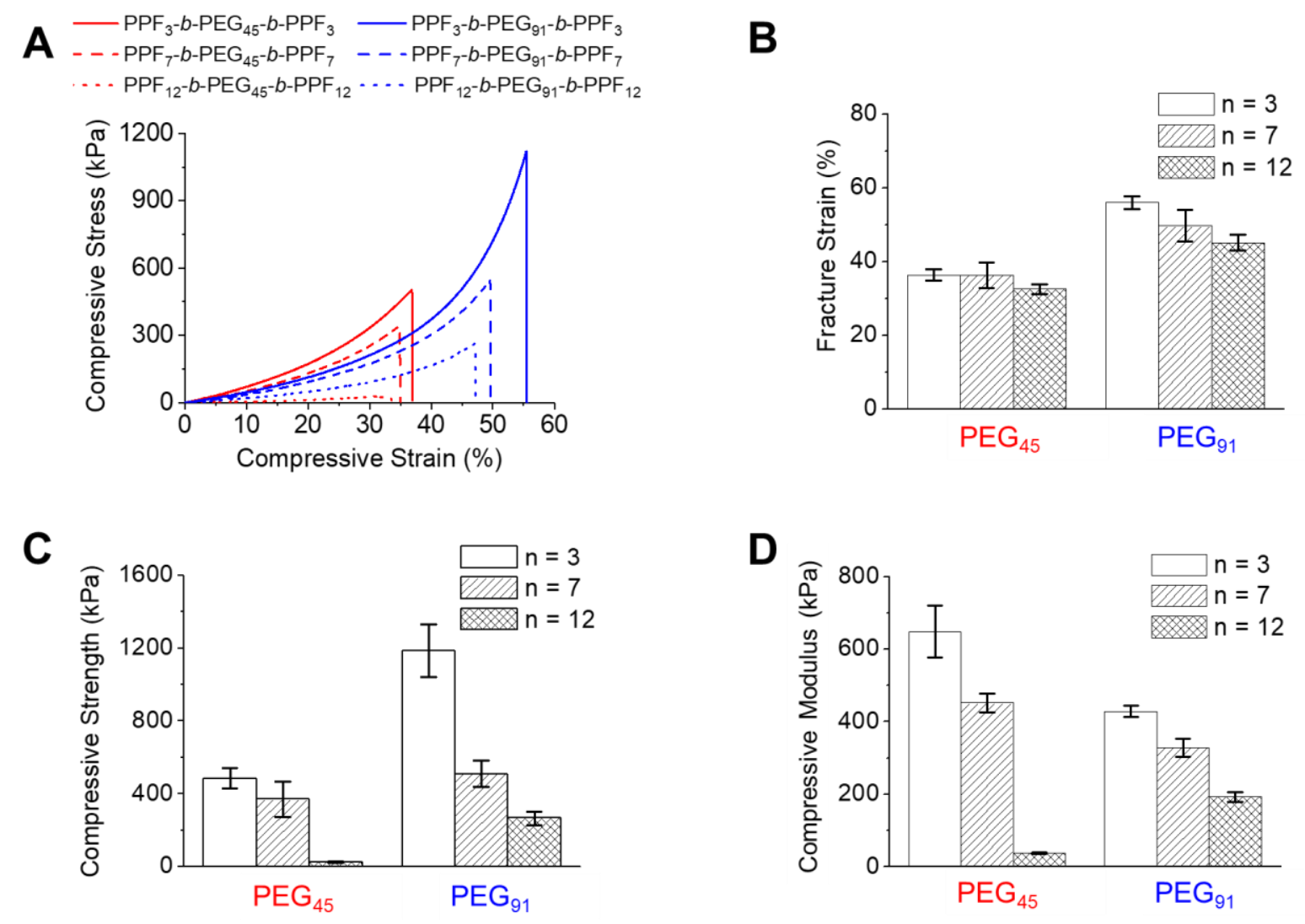

Figure 5. Mechanical properties of $3 \mathrm{D}$ printed $\mathrm{PPF}_{\mathrm{n}}-b-\mathrm{PEG}_{\mathrm{m}}-b-\mathrm{PPF}_{\mathrm{n}}$ hydrogels with different block lengths: (A) representative stress-strain curves, $(\mathbf{B})$ fracture strain, $(\mathbf{C})$ compressive strength and (D) compressive modulus of 3D printed hydrogels with different block lengths (error bars represent \pm standard deviation values on 5 independent measurements). 
Table 2. Values characterizing the mechanical properties of $3 \mathrm{D}$ printed $\mathrm{PPF}_{\mathrm{n}}-b-\mathrm{PEG}_{\mathrm{m}}-b-\mathrm{PPF}_{\mathrm{n}}$ triblock copolymer hydrogels.

\begin{tabular}{cccccccc}
\hline Entry & $\begin{array}{c}\text { DP } \\
\text { PEG }_{\mathbf{m}}\end{array}$ & PPF $_{\mathbf{n}}$ & $\begin{array}{c}\boldsymbol{f} \\
(\mathbf{\%})^{\mathbf{a}}\end{array}$ & $\begin{array}{c}\text { Water content } \\
(\mathbf{\%})\end{array}$ & $\begin{array}{c}\text { Compressive } \\
\text { Modulus } \\
\mathbf{( k P a )}\end{array}$ & $\begin{array}{c}\text { Compressive } \\
\text { Strength (kPa) }\end{array}$ & $\begin{array}{c}\text { Fracture Strain } \\
(\mathbf{\%})\end{array}$ \\
\hline $\mathbf{1}$ & & 3 & 68 & $78.1 \pm 1.2$ & $648.0 \pm 71.5$ & $484.5 \pm 56.4$ & $36.4 \pm 1.6$ \\
$\mathbf{2}$ & 45 & 7 & 48 & $70.1 \pm 2.9$ & $451.9 \pm 26.9$ & $370.3 \pm 97.4$ & $36.3 \pm 3.4$ \\
$\mathbf{3}$ & & 12 & 35 & $69.1 \pm 0.6$ & $37.8 \pm 1.8$ & $26.2 \pm 3.7$ & $32.5 \pm 1.3$ \\
\hline $\mathbf{4}$ & & 3 & 81 & $83.9 \pm 0.6$ & $428.4 \pm 15.6$ & $1186.4 \pm 146.3$ & $56.0 \pm 1.7$ \\
$\mathbf{5}$ & 91 & 7 & 65 & $75.8 \pm 1.2$ & $328.4 \pm 25.0$ & $509.4 \pm 72.1$ & $49.7 \pm 4.3$ \\
$\mathbf{6}$ & & 12 & 52 & $78 . \pm 1.3$ & $193.2 \pm 13.5$ & $266.2 \pm 36.7$ & $45.1 \pm 2.1$ \\
\hline
\end{tabular}

${ }^{\mathrm{a}}$ hydrophilic weight fraction $f=\mathrm{PEG} \overline{M_{n}} /$ total $\overline{M_{n}}$ based on ${ }^{1} \mathrm{H}$ NMR.

Finally, the correlation between the in vitro degradation behavior in PBS and the nanoscale ordering into $\mathrm{PPF}_{\mathrm{n}}-b-\mathrm{PEG}_{\mathrm{m}}-b-\mathrm{PPF}_{\mathrm{n}} \mathrm{ABA}$ triblock copolymer hydrogels was investigated by measuring the remaining dry mass (Figure 6A), the water content (Figure 6B) and the swelling ratio (Figure 6C) over 32 days. Due to PPF hydrolysis, some chains were no longer incorporated in the hydrogel network, leading to mass loss. As shown in Figure 6A, all samples degraded faster at the initial stage, during the first eight days, as there were more PPF to degrade. All hydrogel samples tended to absorb more water and were swollen to a greater extent as the degradation proceeded, indicating a bulk and homogeneous erosion mechanism (Figures 6B and 6C). ${ }^{54}$ Intuitively, $\mathrm{PPF}_{12}-b-\mathrm{PEG}_{45}-b-\mathrm{PPF}_{12}$ and $\mathrm{PPF}_{12}-b-\mathrm{PEG}_{91}-b-\mathrm{PPF}_{12}$ hydrogels, with higher PPF contents and crosslinking sites, should degrade the slowest. But interestingly, these hydrogels displayed the most important degradation rates after 32 days, respectively $39 \%$ and $18 \%$ in mass, and the higher increases of water content and swelling ratios overtime compare to the initial values. Indeed, as shown above, longer hydrophobic PPF blocks tend to favor the formation of crosslinked nanostructures that do not incorporate into the network and a few interconnections between crosslinked domains. Consequently, chains scission via hydrolysis of ester bonds within these 
hydrogels led to a faster separation between crosslinked domains. On the contrary, $\mathrm{PPF}_{7}-b-\mathrm{PEG}_{45}-$ $b-\mathrm{PPF}_{7}$ and $\mathrm{PPF}_{7}-b-\mathrm{PEG}_{91}-b-\mathrm{PPF}_{7}$ combine both relatively long PPF blocks and intern structures allowing crosslinking between PPF domains. These phenomena highlighted that the global hydrophilic weight fraction $f$ of the copolymers and the absolute number of crosslinking sites are not the key parameters driving the degradation rate of such amphiphilic triblock hydrogels. Indeed, the self-assembly behavior leading to the final nanostructure and the interconnection between hydrophobic crosslinked domains is of great importance. 

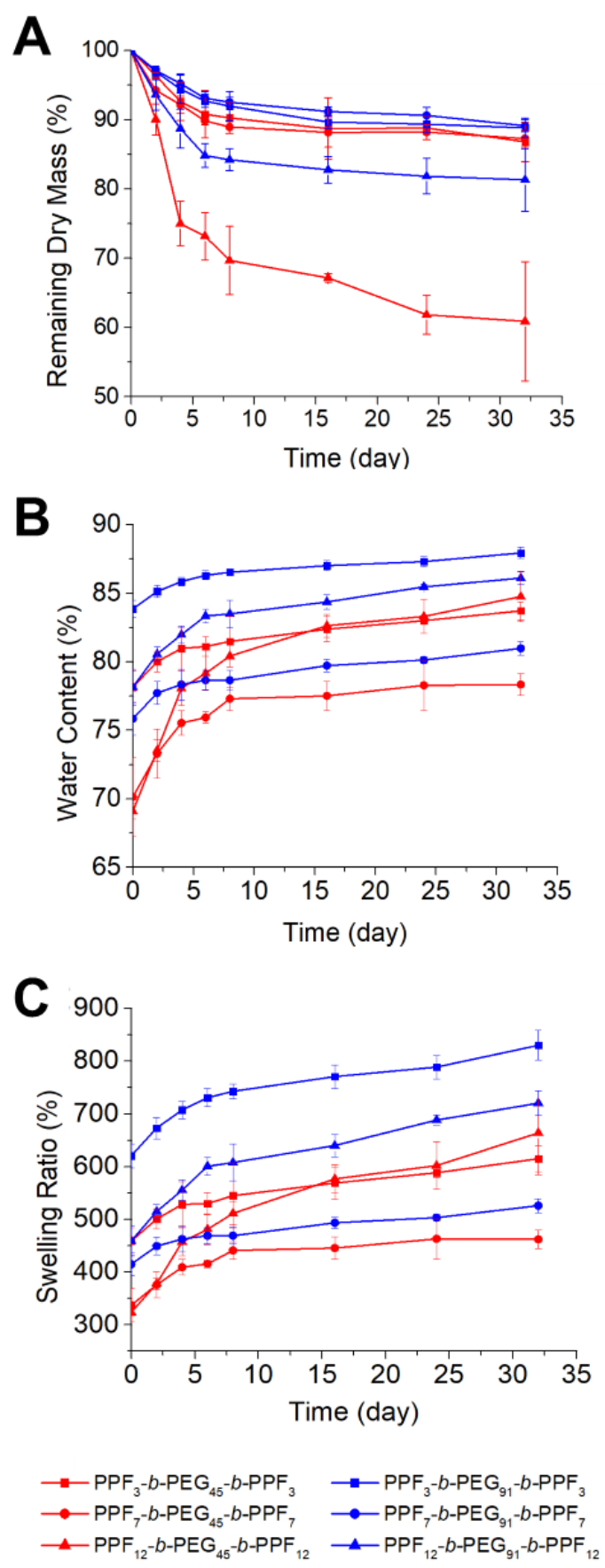

Figure 6. (A) Remaining dry mass, $(\mathbf{B})$ water content, and $(\mathbf{C})$ swelling ratio of $3 \mathrm{D}$ printed $\mathrm{PPF}_{\mathrm{n}^{-}}$ $b-\mathrm{PEG}_{\mathrm{m}}-b-\mathrm{PPF}_{\mathrm{n}}$ triblock copolymer hydrogels during in vitro degradation in PBS. 


\section{Conclusion}

By exploring original topologies of 3D printed covalently crosslinked hydrogels, we herein have demonstrated the remarkable asset represented by the nanophase separation process on the mechanical and degradation properties of $\mathrm{PPF}_{\mathrm{m}}-b-\mathrm{PEG}_{\mathrm{n}}-b-\mathrm{PPF}_{\mathrm{m}}$ amphiphilic networks. Indeed, it was shown that changes in the phase ordering, size, and interconnection resulting from the aggregation mechanisms driven by the block length, are capable of producing mechanically distinguishable hydrogels. Moreover, while number of crosslinking sites are often considered as the key parameter to control the mechanical and resorbability, this work highlights the need of considering how the different crosslinked domains are connected. In the future, these $\mathrm{PPF}_{\mathrm{m}}-b$ $\mathrm{PEG}_{\mathrm{n}}-b-\mathrm{PPF}_{\mathrm{m}}$ based hydrogels could provide insight into the effect of substrate mechanical properties on hMSC differentiation because they are made with the same chemistry, close hydrophilic weight ratios but exhibit a relevant range of mechanical properties.

\section{Acknowledgements}

The authors gratefully acknowledge funding from RESBIO "Integrated Technology Resource for Polymeric Biomaterials" (NIH-NIBIB\&NCMHD P41EB001046) and the National Science Foundation (DMR-1105329) that enabled this work. The authors acknowledge the support of the National Institute of Standards and Technology, U.S. Department of Commerce, in providing the neutron research facilities used in this work. This work utilized facilities supported in part by the National Science Foundation under Agreement No. DMR-1508249. Dr. Boualem Hammouda and Cédric Gagnon from NIST are acknowledged for help and discussions regarding SANS experiments. 


\section{Conflict of Interest Disclosure}

MLB and GLF have submitted provisional patent applications to the University of Akron Research

Foundation covering portions of this work. The patent has been licensed to 21MedTech, LLC.

MLB is a founder, director and equity holder in 21MedTech, LLC.

\section{Supporting Information}

Parameters obtained from the different models used to fit SANS data available in supporting information.

\section{REFERENCES}

1. Ifkovits, J. L.; Burdick, J. A., Photopolymerizable and degradable biomaterials for tissue engineering applications. Tissue engineering 2007, 13 (10), 2369-2385.

2. Riley, L.; Schirmer, L.; Segura, T., Granular hydrogels: emergent properties of jammed hydrogel microparticles and their applications in tissue repair and regeneration. Current opinion in biotechnology 2019, 60, 1-8.

3. Daly, A. C.; Kelly, D. J., Biofabrication of spatially organised tissues by directing the growth of cellular spheroids within 3D printed polymeric microchambers. Biomaterials 2019, 197, 194-206.

4. Daly, A. C.; Riley, L.; Segura, T.; Burdick, J. A., Hydrogel microparticles for biomedical applications. Nature Reviews Materials 2020, 5 (1), 20-43.

5. Nowak, A. P.; Breedveld, V.; Pakstis, L.; Ozbas, B.; Pine, D. J.; Pochan, D.; Deming, T. J., Rapidly recovering hydrogel scaffolds from self-assembling diblock copolypeptide amphiphiles. Nature 2002, 417 (6887), 424.

6. Sun, Y.; Bentolila, L. A.; Deming, T. J., Self-Sorting Microscale Compartmentalized Block Copolypeptide Hydrogels. ACS Macro Letters 2019, 8, 1275-1279.

7. Patrickios, C. S.; Georgiou, T. K., Covalent amphiphilic polymer networks. Current opinion in colloid \& interface science 2003, 8 (1), 76-85.

8. Zhang, H. J.; Sun, T. L.; Zhang, A. K.; Ikura, Y.; Nakajima, T.; Nonoyama, T.; Kurokawa, T.; Ito, O.; Ishitobi, H.; Gong, J. P., Tough physical double-network hydrogels based on amphiphilic triblock copolymers. Advanced Materials 2016, 28 (24), 4884-4890.

9. $\quad$ Strong, L. E.; Dahotre, S. N.; West, J. L., Hydrogel-nanoparticle composites for optically modulated cancer therapeutic delivery. Journal of Controlled Release 2014, 178, 63-68.

10. Sisso, A. M.; Boit, M. O.; DeForest, C. A., Self-healing injectable gelatin hydrogels for localized therapeutic cell delivery. Journal of Biomedical Materials Research Part A 2020, 108 (5), 1112-1121.

11. Li, J.; Mooney, D. J., Designing hydrogels for controlled drug delivery. Nature Reviews Materials 2016, 1 (12), 1-17.

12. Karayilan, M.; Clamen, L.; Becker, M. L., Polymeric Materials for Eye Surface and Intraocular Applications. Biomacromolecules 2021, 22 (2), 223-261. 
13. Kita, M.; Ogura, Y.; Honda, Y.; Hyon, S.-H.; Cha, W.-I.; Ikada, Y., Evaluation of polyvinyl alcohol hydrogel as a soft contact lens material. Graefe's archive for clinical experimental ophthalmology 1990, 228 (6), 533-537.

14. Madl, C. M.; Heilshorn, S. C., Engineering hydrogel microenvironments to recapitulate the stem cell niche. Annual review of biomedical engineering 2018, 20, 21-47.

15. Jia, J.; Jeon, E. J.; Li, M.; Richards, D. J.; Lee, S.; Jung, Y.; Barrs, R. W.; Coyle, R.; Li, X.; Chou, J. C., Evolutionarily conserved sequence motif analysis guides development of chemically defined hydrogels for therapeutic vascularization. Science advances 2020, 6 (28), 5894.

16. Engler, A. J.; Sen, S.; Sweeney, H. L.; Discher, D. E., Matrix elasticity directs stem cell lineage specification. Cell 2006, 126 (4), 677-689.

17. Gilbert, P. M.; Havenstrite, K. L.; Magnusson, K. E.; Sacco, A.; Leonardi, N. A.; Kraft, P.; Nguyen, N. K.; Thrun, S.; Lutolf, M. P.; Blau, H. M., Substrate elasticity regulates skeletal muscle stem cell self-renewal in culture. Science 2010, 329 (5995), 1078-1081.

18. Khetan, S.; Guvendiren, M.; Legant, W. R.; Cohen, D. M.; Chen, C. S.; Burdick, J. A., Degradation-mediated cellular traction directs stem cell fate in covalently crosslinked three-dimensional hydrogels. Nature materials 2013, 12 (5), 458.

19. Brown, T. E.; Silver, J. S.; Worrell, B. T.; Marozas, I. A.; Yavitt, F. M.; Günay, K. A.; Bowman, C. N.; Anseth, K. S., Secondary photocrosslinking of click hydrogels to probe myoblast mechanotransduction in three dimensions. Journal of the American Chemical Society 2018, 140 (37), 11585-11588.

20. Madl, C. M.; Heilshorn, S. C.; Blau, H. M., Bioengineering strategies to accelerate stem cell therapeutics. Nature 2018, 557 (7705), 335.

21. Mondschein, R. J.; Kanitkar, A.; Williams, C. B.; Verbridge, S. S.; Long, T. E., Polymer structureproperty requirements for stereolithographic 3D printing of soft tissue engineering scaffolds. Biomaterials 2017, 140, 170-188.

22. Nadgorny, M.; Ameli, A., Functional polymers and nanocomposites for 3D printing of smart structures and devices. ACS applied materials \& interfaces 2018, 10 (21), 17489-17507.

23. Semenov, A.; Joanny, J.-F.; Khokhlov, A., Associating polymers: equilibrium and linear viscoelasticity. Macromolecules 1995, 28 (4), 1066-1075.

24. Lang, C.; LaNasa, J. A.; Utomo, N.; Xu, Y.; Nelson, M. J.; Song, W.; Hickner, M. A.; Colby, R. H.; Kumar, M.; Hickey, R. J., Solvent-non-solvent rapid-injection for preparing nanostructured materials from micelles to hydrogels. Nature communications 2019, 10 (1), 1-10.

25. Dilla, R. A.; Motta, C. M.; Snyder, S. R.; Wilson, J. A.; Wesdemiotis, C.; Becker, M. L., Synthesis and 3D printing of PEG-poly (propylene fumarate) diblock and triblock copolymer hydrogels. ACS Macro Letters 2018, 7 (10), 1254-1260.

26. Schellekens, H.; Hennink, W. E.; Brinks, V., The immunogenicity of polyethylene glycol: facts and fiction. Pharmaceutical research 2013, 30 (7), 1729-1734.

27. Choi, J.; Kim, K.; Kim, T.; Liu, G.; Bar-Shir, A.; Hyeon, T.; McMahon, M. T.; Bulte, J. W.; Fisher, J. P.; Gilad, A. A., Multimodal imaging of sustained drug release from 3-D poly(propylene fumarate)(PPF) scaffolds. Journal of controlled release 2011, 156 (2), 239-245.

28. Seetharaman, G.; Kallar, A. R.; Vijayan, V. M.; Muthu, J.; Selvam, S., Design, preparation and characterization of $\mathrm{pH}$-responsive prodrug micelles with hydrolyzable anhydride linkages for controlled drug delivery. Journal of colloid interface science 2017, 492, 61-72.

29. Fisher, J. P.; Dean, D.; Mikos, A. G., Photocrosslinking characteristics and mechanical properties of diethyl fumarate/poly (propylene fumarate) biomaterials. Biomaterials 2002, 23 (22), 4333-4343.

30. Fisher, J. P.; Jo, S.; Mikos, A. G.; Reddi, A. H., Thermoreversible hydrogel scaffolds for articular cartilage engineering. Journal of Biomedical Materials Research Part A 2004, 71 (2), 268-274. 
31. Dean, D.; Wolfe, M. S.; Ahmad, Y.; Totonchi, A.; Chen, J. E.-K.; Fisher, J. P.; Cooke, M. N.; Rimnac, C. M.; Lennon, D. P.; Caplan, A. I., Effect of transforming growth factor $\beta 2$ on marrow-infused foam poly (propylene fumarate) tissue-engineered constructs for the repair of critical-size cranial defects in rabbits. Tissue engineering 2005, 11 (5-6), 923-939.

32. Liao, E.; Yaszemski, M.; Krebsbach, P.; Hollister, S., Tissue-engineered cartilage constructs using composite hyaluronic acid/collagen I hydrogels and designed poly (propylene fumarate) scaffolds. Tissue engineering 2007, 13 (3), 537-550.

33. Wang, S.; Kempen, D. H.; Simha, N. K.; Lewis, J. L.; Windebank, A. J.; Yaszemski, M. J.; Lu, L., Photo-cross-linked hybrid polymer networks consisting of poly (propylene fumarate) and poly (caprolactone fumarate): controlled physical properties and regulated bone and nerve cell responses. Biomacromolecules 2008, 9 (4), 1229-1241.

34. Lee, J. W.; Kang, K. S.; Lee, S. H.; Kim, J.-Y.; Lee, B.-K.; Cho, D.-W., Bone regeneration using a microstereolithography-produced customized poly (propylene fumarate)/diethyl fumarate photopolymer 3D scaffold incorporating BMP-2 loaded PLGA microspheres. Biomaterials 2011, 32 (3), 744-752.

35. Bracaglia, L. G.; Yu, L.; Hibino, N.; Fisher, J. P., Reinforced pericardium as a hybrid material for cardiovascular applications. Tissue Engineering Part A 2014, 20 (21-22), 2807-2816.

36. Trachtenberg, J. E.; Placone, J. K.; Smith, B. T.; Fisher, J. P.; Mikos, A. G., Extrusion-based 3D printing of poly (propylene fumarate) scaffolds with hydroxyapatite gradients. Journal of Biomaterials science, Polymer edition 2017, 28 (6), 532-554.

37. Olthof, M. G.; Kempen, D. H.; Herrick, J. L.; Yaszemski, M. J.; Dhert, W. J.; Lu, L., Effect of different sustained bone morphogenetic protein-2 release kinetics on bone formation in poly (propylene fumarate) scaffolds. Journal of Biomedical Materials Research Part B: Applied Biomaterials 2018, 106 (2), 477-487.

38. Wallace, J.; Wang, M. O.; Thompson, P.; Busso, M.; Belle, V.; Mammoser, N.; Kim, K.; Fisher, J. P.; Siblani, A.; Xu, Y., Validating continuous digital light processing (cDLP) additive manufacturing accuracy and tissue engineering utility of a dye-initiator package. Biofabrication 2014, 6 (1), 015003.

39. Childers, E. P.; Wang, M. O.; Becker, M. L.; Fisher, J. P.; Dean, D., 3D printing of resorbable poly (propylene fumarate) tissue engineering scaffolds. Mrs Bulletin 2015, 40 (2), 119-126.

40. Wang, M. O.; Vorwald, C. E.; Dreher, M. L.; Mott, E. J.; Cheng, M. H.; Cinar, A.; Mehdizadeh, H.; Somo, S.; Dean, D.; Brey, E. M., Evaluating 3D-printed biomaterials as scaffolds for vascularized bone tissue engineering. Advanced Materials 2015, 27 (1), 138-144.

41. Luo, Y.; Dolder, C. K.; Walker, J. M.; Mishra, R.; Dean, D.; Becker, M. L., Synthesis and biological evaluation of well-defined poly (propylene fumarate) oligomers and their use in 3D printed scaffolds. Biomacromolecules 2016, 17 (2), 690-697.

42. Wilson, J. A.; Luong, D.; Kleinfehn, A. P.; Sallam, S.; Wesdemiotis, C.; Becker, M. L., Magnesium catalyzed polymerization of end functionalized poly (propylene maleate) and poly (propylene fumarate) for 3d printing of bioactive scaffolds. Journal of the American Chemical Society 2017, 140 (1), 277-284.

43. Lee, K.-W.; Wang, S.; Fox, B. C.; Ritman, E. L.; Yaszemski, M. J.; Lu, L., Poly (propylene fumarate) bone tissue engineering scaffold fabrication using stereolithography: effects of resin formulations and laser parameters. Biomacromolecules 2007, 8 (4), 1077-1084.

44. Walker, J. M.; Bodamer, E.; Kleinfehn, A.; Luo, Y.; Becker, M.; Dean, D., Design and mechanical characterization of solid and highly porous 3D printed poly (propylene fumarate) scaffolds. Progress in Additive Manufacturing 2017, 2 (1-2), 99-108.

45. Wilson, J. A.; Hopkins, S. A.; Wright, P. M.; Dove, A. P., 'Immortal'ring-opening polymerization of $\omega$-pentadecalactone by Mg (BHT) 2 (THF) 2. Polymer Chemistry 2014, 5 (8), 2691-2694. 
46. Shameli, K.; Bin Ahmad, M.; Jazayeri, S. D.; Sedaghat, S.; Shabanzadeh, P.; Jahangirian, H.; Mahdavi, M.; Abdollahi, Y., Synthesis and characterization of polyethylene glycol mediated silver nanoparticles by the green method. International journal of molecular sciences 2012, 13 (6), 6639-6650.

47. Guinier, A.; Fournet, G.; Yudowitch, K. L., Small-angle scattering of X-rays. 1955.

48. Hammouda, B., A new Guinier-Porod model. Journal of Applied Crystallography 2010, 43 (4), 716-719.

49. Beaucage, G., Approximations leading to a unified exponential/power-law approach to smallangle scattering. Journal of Applied Crystallography 1995, 28 (6), 717-728.

50. Beaucage, G., Small-angle scattering from polymeric mass fractals of arbitrary mass-fractal dimension. Journal of Applied Crystallography 1996, 29 (2), 134-146.

51. Luo, Y.; Le Fer, G.; Dean, D.; Becker, M. L., 3D Printing of Poly (propylene fumarate) Oligomers: Evaluation of Resin Viscosity, Printing Characteristics and Mechanical Properties. Biomacromolecules 2019, 20 (4), 1699-1708.

52. Lee, K. Y.; Rowley, J. A.; Eiselt, P.; Moy, E. M.; Bouhadir, K. H.; Mooney, D. J., Controlling mechanical and swelling properties of alginate hydrogels independently by cross-linker type and crosslinking density. Macromolecules 2000, 33 (11), 4291-4294.

53. Fu, J., Triblock Copolymer Micelle-Crosslinked Hydrogels. In Self-Healing and Self-Recovering Hydrogels, Creton, C.; Okay, O., Eds. Springer International Publishing: Cham, 2020; pp 211-241.

54. Göpferich, A., Mechanisms of polymer degradation and erosion. Biomaterials 1996, 17 (2), 103114. 
